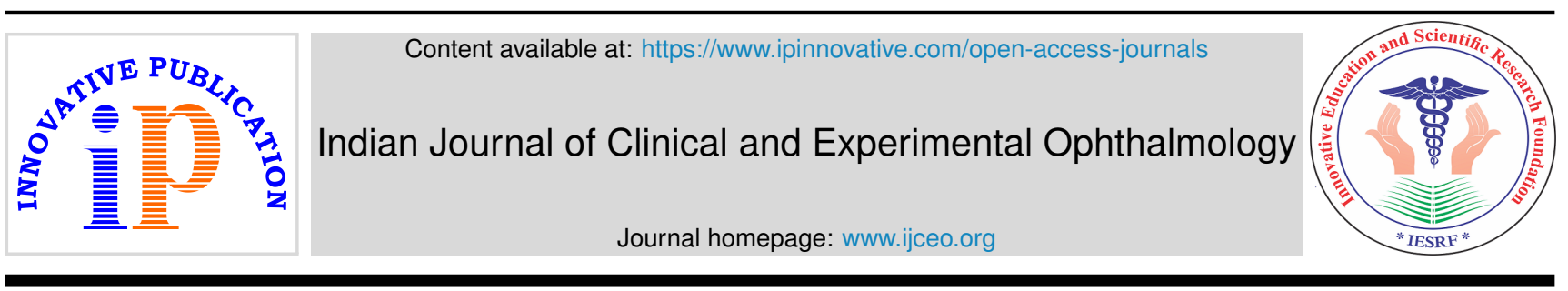

\title{
Editorial
}

\section{Ocular trauma during COVID- 19 crisis: Trends and management}

\author{
Rajendra P Maurya ${ }^{1}$ * \\ ${ }^{1}$ Regional Institute of Ophthalmology, Institute of Medical Sciences, Banaras Hindu University, Varanasi, Uttar Pradesh, India
}

\section{A R T I C L E I N F O}

\section{Article history:}

Received 07-12-2020

Accepted 08-12-2020

Available online 22-12-2020
(C) This is an open access article distributed under the terms of the Creative Commons Attribution License (https://creativecommons.org/licenses/by/4.0/) which permits unrestricted use, distribution, and reproduction in any medium, provided the original author and source are credited.

\section{Dear Friends}

\section{Season's Greetings!}

The outbreak of new 2019 novel corona virus disease (COVID-19) has created serious global threat. During the early phase of pandemic, strict control measures had been implemented such as home isolation, social distancing, restriction on unnecessary travel and outdoor activities. This resulted in unprecedented changes in the lifestyle of people, their psychological state and to the health care system. ${ }^{1}$ COVID-19 crisis has affected ocular trauma in many ways. Several studies have highlighted the changing trends in ocular trauma during the pandemic. The changes have been reported in incidence, epidemiology, mechanism, type of ocular trauma and the way of treatment.

Overall the incidence of trauma has been reduced during the pandemic. Christey et al. reported a $43 \%$ reduction in injury related hospitalization. ${ }^{2}$ Pellegrini et al. from Italy reported a striking $68.4 \%$ decrease in the number of eye trauma during the first month of the pandemic as compared to the same period of previous year. ${ }^{3}$ They reported highest decrease in sport related ocular injuries (from $6.5 \%$ to $0.9 \%$ ). Ocular trauma of mild to moderate severity was expected during a pandemic due to restricted travels and other outdoor \& risk taking activities. There has been a reported increase in the household related ocular injuries during the pandemic. ${ }^{4,5}$ The reported incidence of severe ocular trauma occurring at home during pre-COVID period ranges from 34-48\%. ${ }^{6,7}$ Connine Wu from USA reported the occurrence of only $5.9 \%$ (62 out of 1058 injury) severe ocular trauma during COVID related home stay, amongst them $84 \%$ (52 out of 62) sustained injuries at home.

It has been reported that there was a significant reduction in the number of polytrauma cases due to road traffic accidents and an increase in domestic violence and selfinflicted injury cases during the early COVID crisis due to total lockdown \& home stay. ${ }^{8,9}$ The lockdown resulted in a probable increase in the prevalence of alcohol consumption ${ }^{10}$ which is also an important risk factor for trauma due to physical assault.

The COVID-19 pandemic has changed the course of practice pattern in ocular traumatology owing to the relevant diagnostic and surgical procedures done in case of ocular trauma which are often associated with risk of exposure and transmission of the virus. The eye injuries associated with pan-facial trauma, lid laceration involving nasolacrimal system and naso-ethmoidal orbital fracture are at highest risk due to the high chance of an aerosol-generation and contact with patient's secretions (such as tear, mucous and blood, etc.), therefore all universal precautions should be taken, assuming that the patient is a case of COVID-19.

The elective ophthalmic surgeries have therefore been deferred worldwide during the pandemic. ${ }^{11}$ However, majority of ocular trauma is an emergency, and the treatment cannot be deferred. Although some ocular injuries are not emergency (minor/ superficial injuries and simple uncomplicated orbital fractures) and can be managed in a delayed fashion. The trauma surgeon must weigh the risk and benefits of a delayed conservative approach to the eye 
injury. If surgical intervention is chosen over observation /conservative treatment, every effort should be made to reduce the overall patient stay at the hospital, limit the number of patient care providers and if possible provide trauma care on an OPD basis. Most of the institutions adopted COVID-19 testing of patients and their care provider before hospitalization.

Always follow the basic guidelines for ocular trauma surgery during COVID-19 pandemic;

1. Avoid general anesthesia if possible.

2. PPE for all medical and non-medical supportive staffs as per Government guidelines.

3. Only the essential anaesthetic and allied health staff should be present in the operation theater.

4. Surgeon and their assistant should be outside during intubation and extubation.

5. Use of aerosol protective devices during intubation and extubation.

6. The multidisciplinary surgery should be done in the same setting to avoid repeated exposure to anesthesia.

7. Avoid use of monopolar cautery for cutting and coagulation, better to use bipolar cautery in low power setting.

8. If a planned second surgery is required, it should be performed at least 2 weeks after the primary procedure. $^{12}$

Minimum post-operative follow-up visit is recommended. Telemedicine should be utilized effectively for postoperative follow-up without compromising treatment outcome.

\section{References}

1. Haffajee RL, Mello MM. Thinking Globally, Acting Locally The U.S. Response to Covid-19. N Engl J Med. 2020;382(22):e75. dor:10.1056/nejmp2006/40.

2. Christey G, Amey J, Campbell A, Smith A. Variation in volumes and characteristics of trauma patients admitted to a level4 lockdown for COVID-19 in New Zealand. N Z Med J. 2020;133:81-8.

3. Pellegrini M, Roda M, Geronimo ND, Lupardi E, Giannaccare G, Schiavi C. Changing trends of ocular trauma in the time of COVID-19 pandemic. Eye. 2020;34(7):1248-50. 101:10/038/s41433-0200-0033ه.
4. Chang A, Schnall AH, Law R. Cleaning and disinfectant chemical exposures and temporal associations with COVID-19: National Poison data system. United States, January 1, 2020- March 31 2020. MMWR Morb Mortal Wkly Rep. 2020;69:496-8.

5. Wu C, Patel SN, Jenkins TL, Anthony O, Ho AC, Yonekawa. Ocular trauma during COVID-19 stay-at-home orders: a comparative cohort study. Curr Opin Ophthalmol. 2020;31(5):423-6.

6. Low L, Hodson J, Morris D, Desai P, MacEwen C. Socioeconomic deprivation and serious ocular trauma in Scotland: a national prospective study. $\quad B r \quad J$ Ophthalmol. 2017;101(10):1395-8. doi:10.1136/bjophthalmol-2016-309875

7. Mir TA, Canner JK, Zafar S, Srikumaran D, Friedman DS, Woreta FA. Characteristics of open globe injuries in the United States from 2006 to 2014 . JAMA Ophthalmol. 2020;138(3):268-75.

8. Sidpra J, DAbomeli, Hameed B, Baker J, Mankad K. Rise in the incidence of abusive head trauma during the COVID-19 pandemic. Arch Dis Child. 2020;0:1. 10i:10/136/archdischild-2020-319872

9. Campbell AM. An increasing risk of family violence during the Covid-19 pandemic strengthening community collaborations to save live. Forensic Sci Int. 2020;2:100089. doi:10.1016/1.fsir.2020.100089

10. Rhodes HX, Petersen K, Biswas S. Trauma Trends During the Initial Peak of the COVID-19 Pandemic in the Midst of Lockdown: Experiences From a Rural Trauma Center. Cureus. 2020;12(8). doi:0.7759/cureus.98Tा

11. Ali MJ, Hegde R, Nair AG, Betharia SM, Bhattacharjee K. All India ophthalmological society-Oculoplastics association of India consensus statement on preferred practice in oculoplasty and lacrimal surgery during the COVID-19 pandemic. Indian J Ophthalmol. 2020;68:725-30.

12. Nair AG, Natarajan S, Hegde R, Sundar G, Bapaye MM, Mukherjee $\mathrm{G}$, et al. Guidelines for the management of ocular trauma during the COVID-19 pandemic. Indian J Ophthalmol. 2020;68(11):2483. doi:10.4103/1]0.1]0_1892_20.

\section{Author biography}

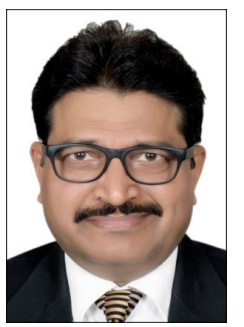

Rajendra P Maurya, (MS, Ph.D) Editor in Chief IJCEO, Associate Professor \& In-charge Orbit, Ocular Oncology and Oculoplasty Unit Regional Institute of Ophthalmology, Institute of Medical Sciences, Banaras Hindu University, Varanasi, (UP), India E-mail: editorijceo@gmail.com, mauryarp_bhu@yahoo.com

Cite this article: Maurya RP. Ocular trauma during COVID- 19 crisis: Trends and management. Indian J Clin Exp Ophthalmol 2020;6(4):478-479. 